\title{
Does sperm supply limit the number of broods produced by a polyembryonous bryozoan?
}

\author{
Andrew J. Pemberton ${ }^{1}$, Lars J. Hansson ${ }^{1,2}$, John D. D. Bishop ${ }^{1, *}$ \\ ${ }^{1}$ Marine Biological Association of the UK, Citadel Hill Laboratory, Plymouth PL1 2PB, UK \\ ${ }^{2}$ Present address: Department of Marine Ecology, University of Göteborg, 40530 Göteborg, Sweden
}

\begin{abstract}
Polyembryony, the splitting of a single sexually produced embryo into many clonal copies, seems to involve a disadvantageous combination of sexual and asexual reproduction, but persists in a diverse range of organisms. It has been suggested that embryonic cloning in cyclostome bryozoans (colonial, sessile marine invertebrates that mate by the release, dispersal and uptake of water-borne sperm) may be a response to sperm limitation. The cyclostome Crisia denticulata inhabits subtidal rock overhangs. Cloned larvae are produced by a colony in a series of independent brood chambers (gonozooids). Offspring from different brood chambers are genetically distinct and are, thus, the outcome of separate fertilisations. We investigated the possibility that sperm limitation reduced female reproductive success at low population density, by assessing the relationship between local colony density, as a proxy for sperm supply, and the number of brood chambers possessed by colonies, as a proxy for fertilisation success. In the patchily distributed population of $C$. denticulata we studied, the number of brood chambers varied enormously between colonies of the same size, and large colonies entirely lacking brood chambers were frequent, suggesting the occurrence of low fertilisation success within many colonies. However, in colonies with broods, only $17 \%$ of the variation in the number of broods per colony could be explained jointly by colony weight and local population density score, with population density being a non-significant predictor in the model. This suggests that sperm supply, as such, does not strongly influence female reproductive success and may, therefore, not be important for the maintenance of polyembryony, at least in the studied population. The wide variation in allocation to female function still requires explanation.
\end{abstract}

KEY WORDS: Sex allocation $\cdot$ Polyembryony $\cdot$ Sperm limitation $\cdot$ Population density $\cdot$ Bryozoa $\cdot$ Crisia

\section{INTRODUCTION}

Polyembryony, the splitting of a single sexually produced embryo into clonal copies, appears to represent a mixture of sexual and asexual reproduction that largely forsakes the respective benefits of the 2 modes. Producing polyembryonous offspring forgoes the genetic diversity inherent within a sexual brood, but nevertheless breaks up the successful parental genotypes and 'bets' instead on a single, unproven genotype (Craig et al. 1997). Despite such an apparent handicap, routine polyembryony appears to have evolved numerous times, being reported in some rust fungi, algae, plants and animals (metazoan phyla include cnidari- ans, platyhelminths, arthropods, bryozoans, echinoderms and chordates; see Craig et al. 1997, Hughes et al. 2005).

The present work focuses on a bryozoan of the order Cyclostomata, a group in which all representatives, with the possible exception of the Cinctiporidae (Boardman et al. 1992), are thought to be polyembryonous (Ryland 1970). Bryozoans are colonial and hermaphroditic, built from replicated zooids budded from a metamorphosed, sexually produced larva. Zooids filter feed with a ciliated, tentacular lophophore. In bryozoans, sperm are released into the water, but eggs are retained, and fertilisation is internal. In the class Gymnolaemata, sperm are known to be brought into contact 
with acting female zooids through the feeding current (Temkin 1994), but sperm collection in the Cyclostomata has not yet been described. Oogenesis in cyclostome bryozoans has been studied most fully within the genus Crisia, in which branching erect colonies consist of rigid internodes of several zooids in a biserial arrangement, joined by flexible, non-calcified joints (nodes). Many oogonia initially form in the developing internode, but most degrade, their host zooids differentiating into autozooids, which produce sperm; on some internodes a developing zooid (rarely $>1$ ) differentiates into a gonozooid, in which the lophophore is transitory (Borg 1926, Ryland 2000). Within the expanded brooding space of the cyclostome gonozooid, polyembryony occurs when a primary embryo repeatedly buds off clumps of cells that, with slight variation between taxa, develop into independent larvae (Harmer 1893, Robertson 1903, Borg 1926). A single gonozooid of C. denticulata can release 10s of larvae upon dissection, and earlier developmental stages are generally also present, indicating ongoing production of young (authors' unpubl. obs.); Borg (1926) notes the common production of $>100$ embryos and larvae from the primary embryo of Crisiella producta. Molecular techniques have confirmed that embryos within individual gonozooids of Crisia denticulata are genetically identical, but different gonozooids on the same colony house genetically distinct embryos, resulting from separate fertilisation events (Hughes et al. 2005).

Several circumstances have been suggested that should favour the evolution and maintenance of polyembryony in animals, but most of these do not seem applicable to algae, plants, or colonial animals, such as cyclostome bryozoans, that mate at a distance by the remote transfer of male gametes (see Pemberton et al. 2007). More applicable explanations envisage polyembryony as making 'the best of a bad job' in the face of constraints on mating opportunities (Craig et al. 1997). Data from a study of Crisia denticulata failed to support a suggestion by Ryland (1996) that polyembryony might be a response to limited gene flow in sessile species in which 'potential mates will differ little, and sexual reproduction may produce larvae with genotypes no less fit within the immediate vicinity than their parent'. A large proportion of the total genetic variability encompassed by 2 widely separated populations of $C$. denticulata was present within patches of colonies in small-scale rock overhangs (Pemberton et al. 2007); thus, potential mates would not be genetically similar.

Ryland (1996) also predicted (echoing an earlier suggestion made for red algae with aflagellate gametes by Searles 1980) that low sperm output from typically small cyclostome colonies, when combined with a sparse adult distribution, gave a low probability that a colony could capture enough sperm to fertilise all the eggs it could potentially produce. This appeared to tie in well with reports in the contemporary literature of sperm-limited reproductive success in many freespawning taxa because of rapid sperm dilution (e.g. Levitan \& Petersen 1995). Here, we address the suggestion by Ryland (1996) that polyembryony is advantageous because it enables cyclostomes to replicate the zygotes resulting from the capture of relatively few sperm. In circumstances where sperm were limiting, the level of brooding would reflect sperm supply. We test the prediction that the number of brood chambers (gonozooids) decreases as sperm become limiting at low population density in Crisia denticulata. If so, this would support Ryland's (1996) premise that sperm limitation is important for the maintenance of polyembryony.

\section{MATERIALS AND METHODS}

Data collection. Colonies of Crisia denticulata were collected by wading and snorkelling at Wembury, near Plymouth, Devon, England (UK national grid reference SX518482). C. denticulata were found on the underside of rock overhangs in the shallow subtidal. Individual overhangs were ca. 1 to $6 \mathrm{~m}$ in length and ca. 0.5 to $2 \mathrm{~m}$ from top to bottom. Each overhang, which might contain one to several thousand colonies, was separated horizontally from adjacent overhangs by ca. 2 to $30 \mathrm{~m}$.

Colonies collected during 2001 (August to October) were those also studied by Pemberton et al. (2007) and were spatially mapped, allowing estimation of local colony density. The location of collected colonies within individual overhangs was established from the $x, y$ position of $5 \times 5 \mathrm{~cm}$ divisions on strung quadrats held against the rock wall. The density of Crisia denticulata across all sampled overhangs was estimated at the level of the $5 \times 5 \mathrm{~cm}$ quadrat divisions (score $0=$ no colonies present; $1=<50 \%$ cover of C. denticulata, generally 1 or 2 colonies; $2=>50 \%$ cover, generally 3 or more colonies). Focal colonies for further analysis were collected, transported individually back to the laboratory and preserved in ethanol as described by Hughes et al. (2005). Further details of the collection sites, including maps, are provided by Pemberton et al. (2007).

Colonies from 11 overhangs representing a range of local densities were haphazardly selected from the ethanol-preserved 2001 collections. Only specimens with well-defined holdfasts were included to ensure the complete colony was measured. Following the removal of epifauna and any other adherent material, colonies were dried at room temperature and weighed 
on an analytical balance. Autozooids made up the vast majority of the weight of a colony, with a much smaller proportion being composed of rhizoids (a further zooidal polymorph with a purely structural function). Gonozooids contributed an insignificant proportion to the total weight, so they were not removed before weighing, nor were final weights adjusted. Regression analysis of a small preliminary data set showed autozooid number to be highly correlated with colony weight $\left(r^{2}=0.986\right)$. There were approximately 120 autozooids $\mathrm{mg}^{-1}$ dry weight. Numbers of gonozooids were recorded. An index of local population density was estimated by adding the 0,1 , or 2 density scores of the relevant $5 \times 5 \mathrm{~cm}$ quadrat divisions surrounding each focal specimen. (The score of the $5 \times 5 \mathrm{~cm}$ square in which the focal colony itself fell was not adjusted, i.e. the focal specimen was included in this calculation.) This potentially allowed estimates of local population density at various spatial scales to be made. However, independent investigation of density dependence across a range of within-overhang spatial scales was not possible, as density measures were highly positively correlated (e.g. $0.25 \times 0.25$ and $1 \times 1 \mathrm{~m}$ sided squares, $\mathrm{r}_{\mathrm{S}}=$ 0.918, $\mathrm{p}<0.0001)$. Therefore, we consider here only the summed scores within a $1 \times 1 \mathrm{~m}$ square surrounding the focal individual (total area $=1 \mathrm{~m}^{2}$ ).

A supplementary collection was made from March to June 2002, but without mapping of colonies to allow estimation of local population density. The weight and number of brood chambers of colonies was determined as for the 2001 samples.

Statistical analysis. Following data collection it became clear that the majority of colonies lacked gonozooids (see 'Results'). Such a dominance of zero values deviated from normality assumptions of parametric statistics and presented an unsuitably large number of ties for rank-based non-parametric tests. Statistical analysis, therefore, progressed in 2 stages. The initial analysis investigated differences in weight and (for 2001) local density between colonies with and without gonozooids. The second part to the analysis focused solely on colonies from the 2001 collection that possessed gonozooids, to explore any possible 3-way relationship between local density, colony weight and gonozooid number.

\section{RESULTS}

\section{Data from collections in 2001}

Local density varied considerably, from isolated individuals to dense stands of Crisia denticulata; the summed density scores for a $1 \mathrm{~m}$ square around a focal colony ranged from 1 to 108 . Colony dry weight varied by $>2$ orders of magnitude $(0.0022$ to $0.4581 \mathrm{~g}) ; 88$ of the 134 colonies scored (i.e. 66\%) possessed no gonozooids, and these non-brooding colonies occurred across almost the entire density range; the maximum number of gonozooids on a single colony was 84 (Fig. 1A).

Colonies that lacked gonozooids weighed less (MannWhitney, $W=4230.5, \mathrm{p}<0.0001$ ), i.e. had fewer autozooids, and were found at lower local density (MannWhitney, $W=4777.5, \mathrm{p}=0.0112$ ) than those colonies possessing 1 or more gonozooids. However, in the 43 colonies that did possess gonozooids and for which a density score was available, no relationship existed between weight and local density $(r=0.080, p=0.611)$. For these colonies, multiple regression revealed a statistically significant overall relationship between log gonozooid number (as the dependent variable), local density and weight (ANOVA, $F=5.33$, p = 0.009, regression equation: $\log$ gonozooids $=0.504+$ 0.00343 [density] +1.79 [weight]) (Fig. 2). However, the trend was extremely weak, with both independent variables together accounting for only $16.9 \%\left(=\mathrm{R}_{\mathrm{adj}}^{2}\right)$ of the variation in log gonozooid number. Local density was a non-significant predictor in the multiple regression $(t=1.69, \mathrm{p}=0.098)$, while the effect of colony weight was significant $(t=2.63, \mathrm{p}=0.012$ ).
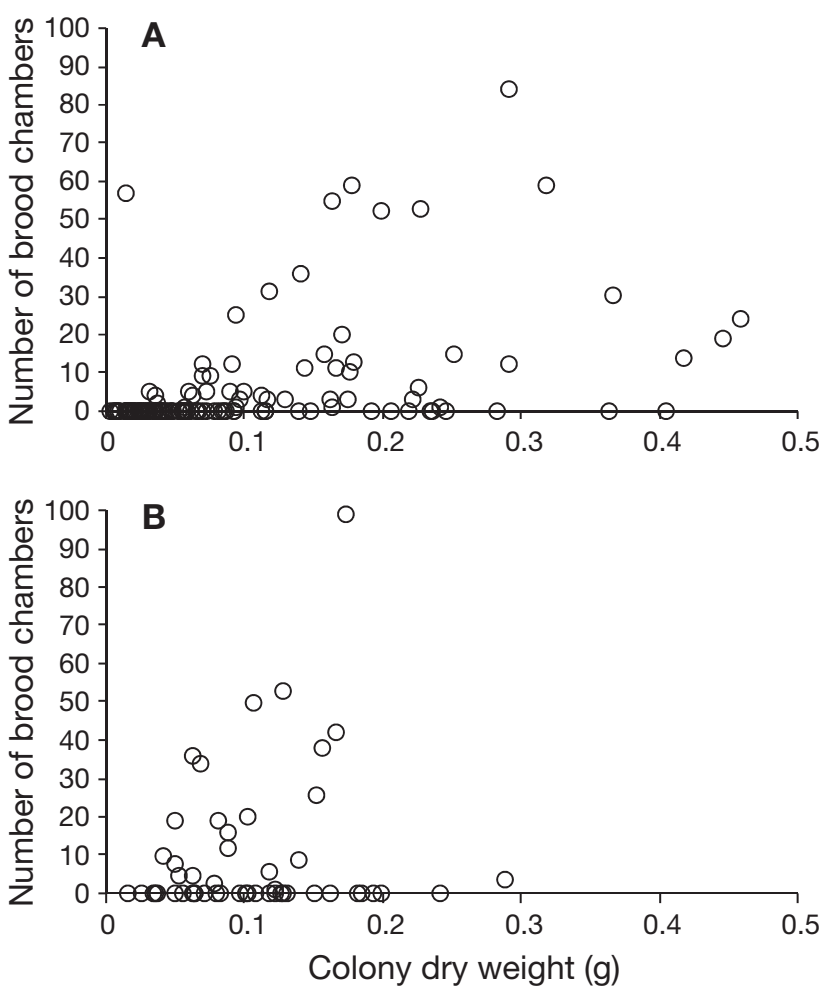

Fig. 1. Crisia denticulata. Relationship between colony dry weight and the number of brood chambers per colony: (A) data from 2001 and (B) data from 2002 


\section{Data from collections in 2002}

Fifty-one colonies were scored. Colony weight varied 19 -fold $(0.0149$ to $0.2873 \mathrm{~g}) ; 29$ of the 51 colonies scored (i.e. $57 \%$ ) possessed no gonozooids; the maximum number of gonozooids on a single colony was 99 (Fig. 1B). Colonies that lacked gonozooids were not different in weight from those possessing 1 or more gonozooids (Mann-Whitney, $W=580.0, \mathrm{p}=0.8866$ ).

A ranking of the combined 2001 and 2002 colonies by weight was divided into 9 groups with increasing weight, each of 20 or 21 colonies. With increasing weight a clear increase in the proportion of colonies

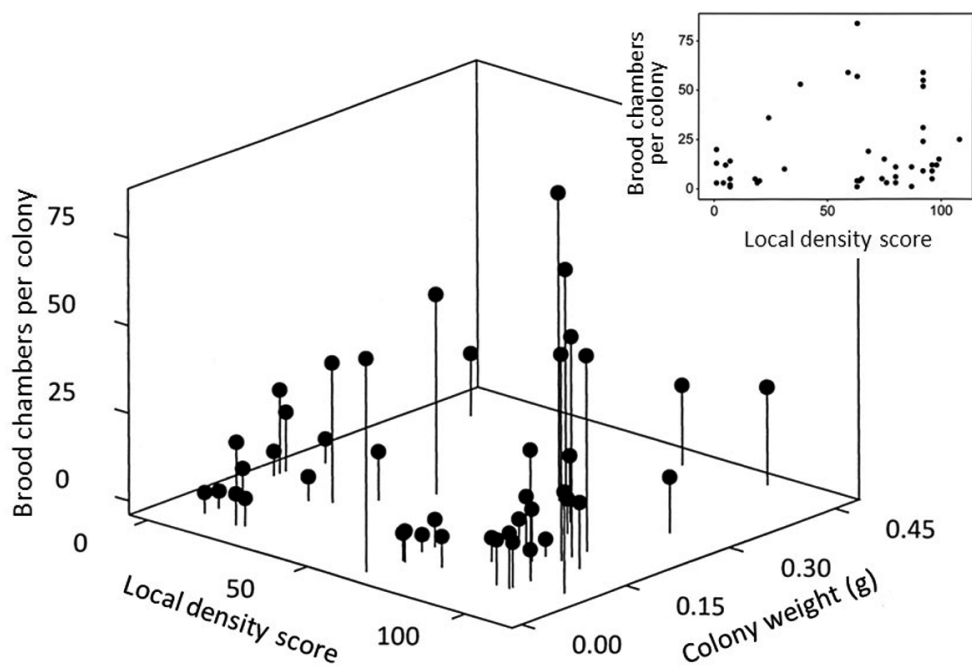

Fig. 2. Crisia denticulata. Relationship of number of brood chambers per colony, colony dry weight and local population density score (1 $\left.\mathrm{m}^{2} \mathrm{scale}\right)$, 2001 data; inset, bivariate scatter plot of brood chambers per colony versus local density score, from the same data set. Only colonies with at least 1 brood chamber were plotted

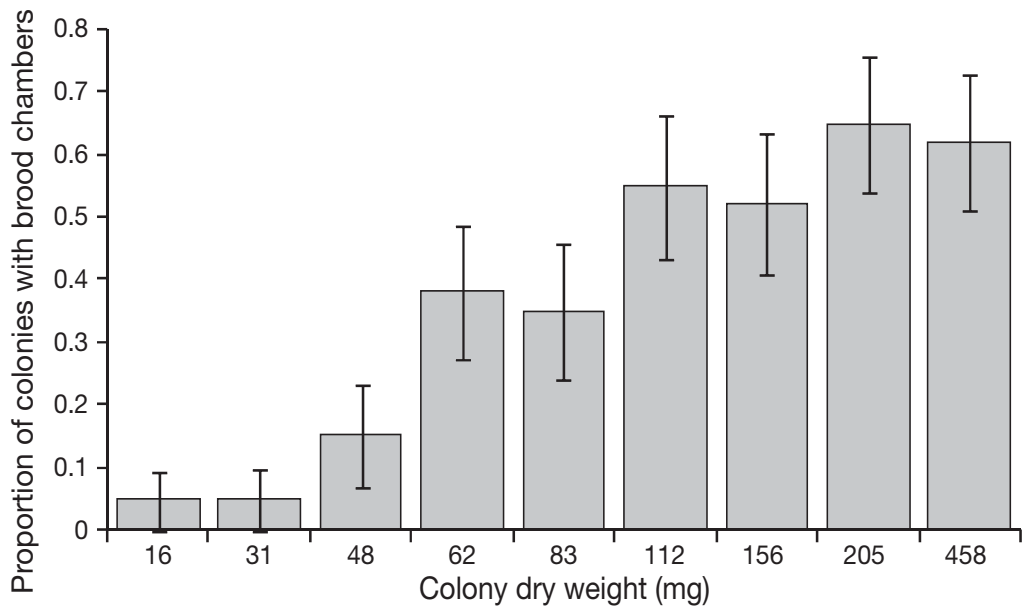

Fig. 3. Crisia denticulata. Proportion $( \pm \mathrm{SD})$ of colonies with brood chambers in 9 weight categories ( $\mathrm{n}=20$ or 21 ) formed by ranking the colonies of the combined 2001 and 2002 data. Values on the $x$-axis represent weight (mg) of the largest colony in each category with brood chambers was evident (binary logistic regression, the probability that slope $=0$ was $<0.001$ ) (Fig. 3). Nevertheless, 35 to $60 \%$ of the colonies above approximately $50 \mathrm{mg}$ (ca. 6000 autozooids) lacked brood chambers.

\section{DISCUSSION}

Although in some species the zooids are single-sex, bryozoan colonies as a whole are hermaphroditic (Ryland \& Bishop 1993). Gonochorism (i.e. single-sex colonies) has been reported in a very few bryozoan species (e.g. Robertson 1903), but in these cases the alternative of sequential hermaphroditism requires careful assessment (Borg 1926). A striking feature of the data presented here for Crisia denticulata is the large proportion of colonies that lack brood chambers altogether, even in the largest size categories. A similar observation (framed as the finding of equal numbers of similar-sized colonies with and without ovicells [i.e. gonozooids]) was presented as evidence of gonochorism in Crisia franciscana in the published abstract by Beauchamp (1984). Three possible patterns of gender allocation with colony growth are presented in Fig. 4. The data for C. denticulata resemble Pattern A, in which female investment ranges from zero to high levels across the range of post-maturation colony sizes. Thus, C. denticulata colonies with no, one, or only a few brood chambers are present at relatively large colony size (Fig. 1). Although colonies of $C$. denticulata without brood chambers could logically be referred to as male (presuming they do produce sperm), they are probably better regarded as the extreme of a continuum of female investment within a hermaphroditic population. It is not known whether the observations underlying Beauchamp's brief report on C. franciscana related to a situation like Pattern A in Fig. 4, or to Pattern $\mathrm{C}$, in which a clear separation between fully male and fully female sexual investment exists. However, our own data gave very little support for the existence of truly separate sexes in C. denticulata.

The extreme variability in levels of female investment in Crisia denticulata requires explanation. The probability that a colony has any brood chambers at all is clearly influenced by colony size (Fig. 3), and, with a single exception, colonies with a dry weight $<25$ mg (n = 39) did not possess brood cham- 


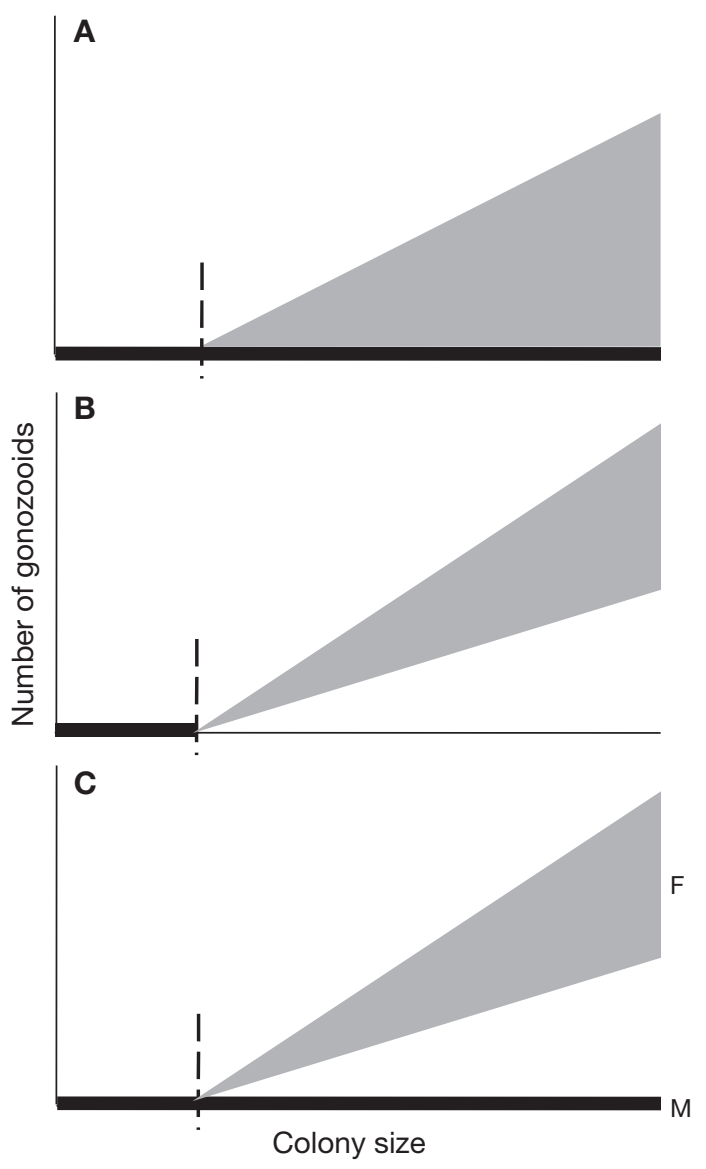

Fig. 4. Some possible patterns of gender allocation in an organism such as Crisia denticulata. Thick line along the $x$-axis represents colonies lacking gonozooids. Dashed vertical line represents onset of sexual maturity, here presumed to occur at a set colony size. (A) Simultaneous hermaphroditism accompanied by extreme variability in female investment, resulting in a proportion of colonies lacking gonozooids at all sizes. (B) Simultaneous hermaphroditism accompanied by only moderate variability in female investment, so that all post-maturity colonies have at least some gonozooids. (C) Gonochorism (with moderate variability in female investment, F); postmaturity colonies without gonozooids are males $(\mathrm{M})$

bers, suggesting that the smallest colonies analysed were predominantly immature as females. Colony weight was a significant predictor of the number of brood chambers per colony in the 2001 data set (with the statistical analysis constrained to those colonies with 1 or more chambers). Nevertheless, the wide variation in the number of brood chambers per colony, even when comparing colonies of similar size, is notable in both the 2001 and 2002 data (Fig. 1). The main possibility we wished to investigate here was that the brooding activity of colonies was influenced by the sperm supply experienced by each, under the hypothesis that the most isolated colonies are undergoing sperm limitation, restricting the production of broods.
Local population density surrounding each focal specimen varied considerably from the absence of neighbours to dense stands of $C$. denticulata. This could have partially explained the variation in brooding observed and would relate to the maintenance of polyembryony within the cyclostomes. In fact, there was very little indication of an effect of estimated colony density on the number of brood chambers in colonies possessing any chambers at all, although colonies without brood chambers occurred at a lower median density than those with chambers. It seems that, at most, local population density, as estimated here, had only a minor effect on female reproductive investment. Thus, our study of the effect of local density in this population of $C$. denticulata presents little direct evidence that sperm limitation is a likely explanation for polyembryony.

Since Ryland (1996) speculated on the possible role of polyembryony in counteracting sperm limitation, evidence has been accumulating that the dynamics of fertilisation in species that, like Crisia denticulata, retain their eggs and release sperm into the surrounding water-so-called spermcast mating species (Pemberton et al. 2003, Bishop \& Pemberton 2006) or eggbrooding free-spawners (Johnson \& Yund 2004) - may differ greatly from the external fertilisation models based largely on broadcast-spawning echinoderms (McCartney 1997, Bishop 1998, Yund 2000, Pemberton et al. 2003, Johnson \& Yund 2004, Bishop \& Pemberton 2006). The essence of Ryland's (1996) argument that sperm production in cyclostome bryozoans will be low compared to the better studied large-bodied external fertilisers is almost certainly correct. It is much less certain, given their ability to gather sperm from very low concentrations (e.g. Pemberton et al. 2003, Phillippi et al. 2004, Yund et al. 2007; for colonial ascidians and cheilostome bryozoans), that cross fertilisation is unreliable in suspension-feeding spermcasters. Accordingly, sperm limitation may not have been experienced within the range of local population densities investigated in the present study. However, caution may be required in extrapolating fertilisation data from other taxa, as direct tests have not been performed on any cyclostome species; cyclostomes have a relatively simple form of filter feeding (Nielsen \& Riisgård 1998), which may have significance for efficiency of sperm capture and avoidance of sperm ingestion (J. S. Ryland pers. comm.). Also, some species of cyclostome are found at much lower population densities than C. denticulata (Hayward \& Ryland 1985, J. S. Ryland pers. com.). Future work should address different spatial scales of potential density dependence, both in natural populations and artificial experiments, to test experimentally at what level of sperm supply female reproductive output becomes compromised. 
In searching for an explanation for the prevalence of polyembryony within the group, we cannot completely discount the possibility that this reproductive mode was an adaptation in the common ancestor of cyclostome bryozoans and that its persistence is attributable to phylogenetic constraint (Hughes et al. 2005). However, the trade-off between the number of gonozooids per colony and the number of cloned larvae produced per gonozooid would appear highly susceptible to adjustment over evolutionary time. If polyembryony were an evolutionary relic, presently disadvantageous because of the lack of genetic diversity amongst progeny, the routine production of multiple gonozooids each producing only a few larvae (or ultimately 1) would be predicted, given sufficient sperm supply. In fact, despite the absence of a clear effect of local density, the overall pattern of occurrence of gonozooids within the study population of $C$. denticulata indicates that fertilisation success within a colony is often low, suggesting that the 'amplification' of relatively rare fertilisations remains a viable explanation for the current maintenance of polyembryony in cyclostomes. A parallel argument is provided by Ryland (2000), who reported considerable variation in the position of gonozooids along fertile internodes of various Crisia species, including $C$. denticulata, in contrast to the statement by Borg (1926). On this basis, Ryland suggested that the development of gonozooids was governed by rare fertilisation events.

The pattern of female investment noted here may not be restricted to Crisia denticulata; Harmer (1896, p. 72) remarked that, in most cyclostomes, 'ovicells (gonozooids) are not present in a very large proportion of the colonies which may be examined'. This situation is not new. Studying fossilised encrusting cyclostomes from the Mesozoic era, McKinney \& Taylor (1997, p. 552) noted: 'Most colonies that reached the size at which reproduction could occur within their species failed to produce brood chambers.' In 15 Mesozoic species, the percentage of colonies possessing brood chambers ranged from 2.5 to $88 \%$ (McKinney \& Taylor 1997); the percentage for $C$. denticulata in the present study ( $37 \%$ over both data sets) falls near the centre of the distribution of values for the fossils. In contrast, Harmer (1896) reported that all colonies of the present-day species Lichenopora verrucaria possessed a brood chamber, the development of which was initiated very early in colony growth, at the 3-zooid stage. Clearly, the determinants of the very wide range of female investment in one species documented here and the exact nature and mechanism of gender allocation in crisiids and other cyclostomes require further study. Such work would benefit from a parallel investigation of sperm production by autozooids, which would involve techniques additional to the simple external observations reported here.
Acknowledgements. This work was supported by the Natural Environment Research Council through Grant NER/M/S/ 2001/00112 and a grant-in-aid to the Marine Biological Association of the UK We thank Mike Temkin, Paul Taylor and 3 anonymous referees for comments that substantially improved the paper.

\section{LITERATURE CITED}

Beauchamp KA (1984) Reproductive dynamics in the cyclostome bryozoan, Crisia franciscana. Am Zool 24:130A

Bishop JDD (1998) Fertilization in the sea: Are the hazards of broadcast spawning avoided when free-spawned sperm fertilize retained eggs? Proc R Soc Lond B Biol Sci 265: 725-731

Bishop JDD, Pemberton AJ (2006) The third way: spermcast mating in sessile marine invertebrates. Integr Comp Biol 46:398-406

Boardman RS, McKinney FK, Taylor PD (1992) Morphology, anatomy, and systematics of the Cinctiporidae, new family (Bryozoa: Stenolaemata). Smithson Contrib Paleobiol 70: $1-81$

Borg F (1926) Studies on recent cyclostomatous Bryozoa. Zoolog Bidrag Uppsala 10:181-507

Craig SF, Slobodkin LB, Wray GA, Biermann CH (1997) The 'paradox' of polyembryony: a review of the cases and a hypothesis for its evolution. Evol Ecol 11:127-143

Harmer SF (1893) On the occurrence of embryonic fission in cyclostomatous Polyzoa. Q J Microsc Sci 34:199-241

Harmer SF (1896) On the development of Lichenopora verrucaria, Fabr. Q J Microsc Sci 39:71-144

Hayward PJ, Ryland JS (1985) Cyclostome bryozoans, No. 34 In: Kermack DM, Barnes RSK (eds) Synopses of the British fauna. E. J. Brill/Dr W. Backhuys Press, Leiden

Hughes RN, D'Amato ME, Bishop JDD, Carvalho GR and others (2005) Paradoxical polyembryony? Embryonic cloning in an ancient order of marine bryozoans. Biol Lett 1: $178-180$

Johnson SL, Yund PO (2004) Remarkable longevity of dilute sperm in a free-spawning colonial ascidian. Biol Bull (Woods Hole) 206:144-151

Levitan DR, Petersen C (1995) Sperm limitation in the sea. Trends Ecol Evol 10:228-231

- McCartney MA (1997) Sex allocation and male fitness gain in a colonial, hermaphroditic marine invertebrate. Evolution 51:127-140

McKinney FK, Taylor PD (1997) Life histories of some Mesozoic encrusting cyclostome bryozoans. Palaeontology 40: 515-556

Nielsen C, Riisgård HU (1998) Tentacle structure and filterfeeding in Crisia eburnea and other cyclostomatous bryozoans, with a review of upstream-collecting mechanisms. Mar Ecol Prog Ser 168:163-186

Pemberton AJ, Hughes RN, Manríquez PH, Bishop JDD (2003) Efficient utilisation of very dilute aquatic sperm: sperm competition may be more likely than sperm limitation when eggs are retained. Proc R Soc Lond B Biol Sci 270(Suppl 2):S223-S226

Pemberton AJ, Hansson LJ, Craig SF, Hughes RN, Bishop JDD (2007) Microscale genetic differentiation in a sessile invertebrate with cloned larvae: investigating the role of polyembryony. Mar Biol 153:71-82

> Phillippi A, Hamann E, Yund PO (2004) Fertilization in an egg-brooding colonial ascidian does not vary with population density. Biol Bull (Woods Hole) 206:152-160

Robertson A (1903) Embryology and embryonic fission in the 
genus Crisia. Univ Calif Publ Zool 1:115-156

Ryland JS (1970) Bryozoans. Hutchinson \& Co., London

Ryland JS (1996) Polyembryony 'paradox': the case of cyclostomate Bryozoa. Trends Ecol Evol 11:26

Ryland JS (2000) Gonozooid placement and branching patterns in some species of Crisia (Cyclostomatida). In: Herrera Cubilla A, Jackson JBC (eds) Proceedings of the 11th international Bryozoology Association conference, 26-31 Jan 1998. Smithsonian Tropical Research Institute, Balboa, p 343-354

Ryland JS, Bishop JDD (1993) Internal fertilisation in hermaphroditic colonial invertebrates. Oceanogr Mar Biol

Submitted: April 27, 2010; Accepted: January 7, 2011
Annu Rev 31:445-477

Searles RB (1980) The strategy of the red algal life history. Am Nat 115:113-120

Temkin MH (1994) Gamete spawning and fertilization in the gymnolaemate bryozoan Membranipora membranacea. Biol Bull (Woods Hole) 187:143-155

Yund PO (2000) How severe is sperm limitation in natural populations of marine free-spawners? Trends Ecol Evol 15:10-13

Yund PO, Murdock K, Johnson SL (2007) Spatial distribution of ascidian sperm: two-dimensional patterns and short vs. time-integrated assays. Mar Ecol Prog Ser 341:103-109

Proofs received from author(s): April 14, 2011 